Fecha de recepción: octubre 2019 Fecha de aceptación: diciembre 2019 Versión final: diciembre 2021

\section{Hecho en México para ojos extranjeros: uso y menosprecio de referentes identitarios nacionales en el diseño de productos de consumo}

Leonardo Mora Lomelí ${ }^{1}$, Gabriel OrozcoGrover ${ }^{2}$ y Aurea Santoyo Mercado ${ }^{3}$

\begin{abstract}
Resumen: La identidad cultural mexicana, con sus valores prehispánicos y riqueza étnica, es una vasta fuente de referentes conceptuales, simbólicos y visuales para la construcción de piezas de comunicación, identidad gráfica y diseño de envases para productos y servicios de origen nacional, sin embargo, este recurso sólo suele ser aprovechado cuando se orienta al sector turístico, ya que su uso en productos de consumo habitual suele ser considerado como de menor valor o calidad por parte del consumidor. Este análisis pretende evidenciar ésta situación, así como contrastar el potencial creativo y comercial que puede aportar el uso de referentes identitarios nacionales en el diseño de envase y comunicación. En la actualidad son pocos los casos en los que este potencial se explota en el diseño de piezas que habrán de distribuirse de manera cotidiana en el territorio nacional mexicano, siendo lo más común encontrar mercancías que replican visual y conceptualmente diversas tendencias gráficas emanadas o empleadas en el mercado norteamericano, repercutiendo con ello en una limitada y esporádica creación de valor a través de marcas con identidad cultural mexicana, diluyendo la posibilidad de dotarlos de un alto valor simbólico, histórico y comunicacional.
\end{abstract}

Palabras clave: Identidad mexicana - Diseño de envase - Diseño nacional - Hecho en México - Referentes prehispánicos.

[Resúmenes en inglés y portugués en las páginas 256-257]

(1) Leonardo Mora Lomelí: Licenciado en Diseño y Comunicación Gráfica, Maestro en Diseño Gráfico y Doctor en Humanidades. Profesor Titular, miembro del Cuerpo Académico UDG-CA-790 "Procesos de Comunicación y Educación Superior" y Jefe del Laboratorio de Tipografía y Diseño Editorial del Centro Universitario de Arte, Arquitectura y Diseño de la Universidad de Guadalajara. Empresario, ponente y autor de publicaciones nacionales e internacionales. Estudia el puente entre las humanidades y el diseño gráfico. Mail: dgleonardomora@gmail.com

(2) Gabriel Orozco-Grover: Licenciado en Diseño y Comunicación Gráfica y Maestro en Mercadotecnia por la Universidad de Guadalajara. Doctor en Marketing por la Universitat de València, España. Diseñador y gestor de proyectos de diseño y comunicación gráfica 
en México y España. Coautor del “Glosario de Producción Gráfica”, UdeG 2009. Autor de artículos: "La creación de valor de marca por medio de patrocinios en eventos deportivos en el mundo”, Zincografía 2018; “Y en preprensa ¿cómo andamos?”, 2010 Quadra, Diseño y Comunicación Visual. Profesor/investigador, miembro del Cuerpo académico UDG CA734 “Diseño, innovación y comunicación”. Actualmente es coordinador de la Maestría en Diseño y Desarrollo de Nuevos Productos en la Universidad de Guadalajara, México. Mail: gabriel.ogrover@academicos.udg.mx

${ }^{(3)}$ Aurea Santoyo Mercado: Diseñadora gráfica, Maestra en Diseño y Desarrollo de Nuevos Productos UdeG, doctorando en el programa Metodología de la Enseñanza. Docente titular de tiempo completo con perfil PRODEP y jefe del Departamento de Proyectos de Comunicación UdeG 2013-2019. Miembro del cuerpo académico UDG CA-790. Participó en el curso de actualización de diseño de envases con Adrián Pierini, 2015. Ha publicado en diversos medios artículos sobre diseño y educación. Mail: aurea.santoyo@cuaad. udg.mx

\section{Introducción}

La identidad cultural mexicana, con sus valores prehispánicos y riqueza étnica, es una vasta fuente de referentes conceptuales, simbólicos y visuales para la construcción de piezas de comunicación, identidad gráfica y diseño de envases para productos y servicios de origen nacional, sin embargo, este recurso sólo suele ser aprovechado cuando se orienta al sector turístico, ya que su uso en productos de consumo habitual suele ser considerado como de menor valor o calidad por parte del consumidor. Este análisis pretende evidenciar esta situación, así como contrastar el potencial creativo y comercial que puede aportar el uso de referentes identitarios nacionales en el diseño de envase y comunicación.

En la actualidad son pocos los casos en los que este potencial se explota en el diseño de piezas que habrán de distribuirse de manera cotidiana en el territorio nacional mexicano, siendo lo más común encontrar mercancías que replican visual y conceptualmente diversas tendencias gráficas emanadas o empleadas en el mercado estadounidense, repercutiendo con ello en una limitada y esporádica creación de valor a través de marcas con identidad cultural mexicana, diluyendo la posibilidad de dotarlos de un alto valor simbólico, histórico y comunicacional.

González-Varas (1999, p. 21) afirma que "los bienes que integran el patrimonio cultural existen desde el mismo momento en que el hombre deja testimonios materiales de su presencia y actividades, dando lugar a objetos de todo tipo, desde obras de arte hasta objetos de carácter utilitario". 


\section{Diseño gráfico mexicano}

El diseño gráfico es una de las disciplinas que mayor impacto ha tenido a partir de la globalización, ya que el continuo uso y consumo de productos provenientes de cualquier parte del mundo, la necesidad de que sea entendido por cualquiera en cualquier parte sin tomar en cuenta aspectos culturales, así como la facilidad del poder consultar y observar propuestas de todas partes del mundo, ha marcado una influencia sin valores culturales y con la falta de originalidad en muchos de los casos. "Los fenómenos de globalización pueden entenderse como una intensificación de las relaciones económicas de ámbito mundial que vinculan espacios geográficos distantes" (Koc, 1994), de igual manera es de suma importancia poder tomar en cuenta tal como lo señala Moya (2006) estudiar los valores estéticos ancestrales, revisar la historia, aspectos sociales y culturales, políticos y religioso para lograr productos con un soporte cultural.

De acuerdo con Manríquez Durán y Castro Silva (2007), por su naturaleza, la globalización es paradójica y compleja, es uniformidad y diversidad a la vez [...] mientras que la cultura es un proceso de reproducción, reestructuración y sobredeterminación de diferencias, no de supresión de ellas. Por tanto, imaginar una cultura única, idéntica y global no es consistente con este planteamiento, pues la mundialización no implica la desaparición ni el aniquilamiento de otras culturas, sino una multiplicidad de visiones del mundo y transformaciones cimentadas en la hibridez y los intercambios.

Siguiendo a Molano (2007) el concepto de identidad cultural encierra un sentido de pertenencia a un grupo social con el cual se comparten rasgos culturales, como costumbres, valores y creencias. La identidad no es un concepto fijo, sino que se recrea individual y colectivamente y se alimenta de forma continua de la influencia exterior.

La identidad cultural de un pueblo viene definida históricamente a través de múltiples aspectos en los que se plasma su cultura, como la lengua, instrumento de comunicación entre los miembros de una comunidad, las relaciones sociales, ritos y ceremonias propias, o los comportamientos colectivos, esto es, los sistemas de valores y creencias [...]. Un rasgo propio de estos elementos de identidad cultural es su carácter inmaterial y anónimo, pues son producto de la colectividad (González-Varas, 1999, p. 43).

De acuerdo con Giménez (2002) citado en extenso,

La identidad es un conjunto de repertorios culturales interiorizados (representaciones, valores, símbolos), a través de los cuales los actores sociales (individuales y colectivos) demarcan sus fronteras y se distinguen de los demás actores en una situación determinada, todo ello dentro de un espacio históricamente específico y socialmente estructurado (p. 412).

El concepto de identidad cultural surgió en los años cincuenta en los Estados Unidos. En ese momento el equipo de investigación de psicología social intentaba encontrar una he- 
rramienta adecuada para dar cuenta de los problemas de la integración de los migrantes (Cuche, 1999).

\begin{tabular}{|l|l|}
\hline Concepto & Definición \\
\hline Cultura: & $\begin{array}{l}\text { Es el conjunto de los rasgos distintivos, espirituales, materiales y afectivos que } \\
\text { caracterizan una sociedad o grupo social. Ella engloba, además de las artes y las } \\
\text { letras, los modos de vida, los derechos fundamentales del ser humano, los siste- } \\
\text { mas de valores, creencias y tradiciones. }\end{array}$ \\
\hline Diversidad cultural: & $\begin{array}{l}\text { Multiplicidad de formas en que se expresan las culturas de los grupos y socieda- } \\
\text { des. Estas expresiones se transmiten dentro y entre los grupos y las sociedades. }\end{array}$ \\
\hline Contenido cultural: & $\begin{array}{l}\text { Sentido simbólico, la dimensión artística y los valores culturales que emanan de las } \\
\text { identidades culturales que las expresan. }\end{array}$ \\
\hline Expresiones culturales: & $\begin{array}{l}\text { Son las expresiones resultantes de la creatividad de las personas, grupos y socie- } \\
\text { dades, que poseen un contenido cultural. }\end{array}$ \\
\hline $\begin{array}{l}\text { Actividades, bienes y } \\
\text { servicios culturales: }\end{array}$ & $\begin{array}{l}\text { Son los que desde el punto de vista de su calidad, utilización o finalidad específicas, } \\
\text { encarnan o transmiten expresiones culturales, independientemente del valor co- } \\
\text { mercial que puedan tener. Las actividades culturales pueden constituir una finalidad } \\
\text { de por sí, o contribuir a la producción de bienes y servicios culturales. }\end{array}$ \\
\hline Interculturalidad: & $\begin{array}{l}\text { Presencia e interacción equitativa de diversas culturas y la posibilidad de generar } \\
\text { expresiones culturales compartidas, adquiridas por medio del diálogo y de una } \\
\text { actitud de respeto mutuo. }\end{array}$ \\
\hline
\end{tabular}

Tabla 1. Definiciones de la UNESCO. Fuente: UNESCO (2019, s/p).

Siguiendo a Rentería (2005), del concepto de identidad se deriva otro que es el de la etnicidad, que por su importancia que ha tomado a últimas fechas con el auge del movimiento indígena latinoamericano es importante retomarlo tal y como lo define Chihu (2002): La etnicidad tienen sus fundamentos en los profundos vínculos primordiales de un grupo; es decir, lazos fundados en un territorio común, parentesco y vínculos de sangre, lenguaje, religión, costumbres. A la vez debe tomar en cuenta cómo este fenómeno sociocultural es usado como instrumento político con el propósito de obtener beneficios para el grupo. Considerando las definiciones manifestadas por la UNESCO, podemos iniciar un estudio acerca de las particularidades de la cultura y manifestaciones culturales de nuestras raíces mexicanas, se puede observar claramente en los aún existentes grupos indígenas, los cuales cuentan con una gran diversidad de lenguas y pueblos o grupos indígenas en el país y que varios se integran al interior por distintos grupos étnicos. Una cuestión que identifica a los pueblos indios de nuestro país es que tienen diferentes culturas y representan a diferentes etnias, esto hace que México sea un país multicultural y pluriétnico (Rentería, 2005). Por lo que en líneas posteriores se mencionará a los veinte grupos indígenas con mayor población en México, como referente de la diversidad cultural antes mencionada. 
Ubicados en el Norte del país están presentes los Mayos y en el Noreste los Tarahumaras y Huastecos; en el centro del país se encuentran los Nahuas conformados por siete grupos étnicos, los totonacas, los Mazahuas y en la zona centro y un poco más al occidente los Otomies y Purépechas. Por otra parte la mayoría de estos veinte principales grupos indígenas se ubican al sur del país, esparcidos en diversos estados, entre ellos Tabasco, Chiapas, Oaxaca y Guerrero donde están presentes los Mayas, Chontales, Zoques, Tlapanecos, Mixes, Choles, Chinantecas, Mazatecos, Tsotsiles, Tzeltales, Zapotecas y Mixtecas (Cisneros, 2019).

Tan sólo de estos 20 grupos indígenas, se puede mostrar y exaltar una gran diversidad de recursos gráficos utilizados como parte de su vestimenta, en artesanías y otras manifestaciones, así como la utilización del color en cada una de ellas que hacen uso de contrastes y colores vivos como rojos, rosas, azules, verdes y morados, creando propuestas contrastantes y complementarias en estas gamas cromáticas (Ver Figuras 1 y 2). Todas las formas diseñadas por el hombre son provenientes de historias socioculturales. Existen arquetipos que implican significados culturales que se usan como contextos simbólicos, como lo serían la forma de un objeto, su función, usabilidad y calidad. En el diseño el uso de ornamentos, formas y líneas siempre han sido parte de la identidad cultural (Williams, 1990).
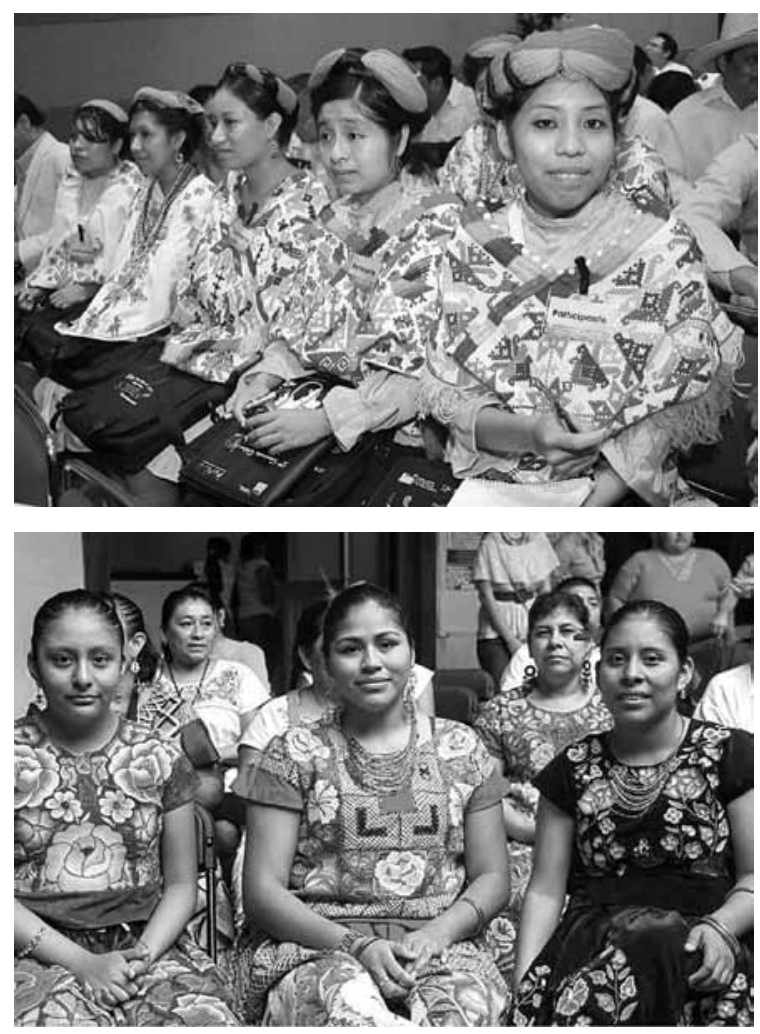

Figuras 1 y 2. Vestimenta típica de mujeres indígenas (Milenio Digital, 2018, s/p) e (Ibero $90.92019, \mathrm{~s} / \mathrm{p})$. 
La identidad se construye por medio de un sistema de símbolos y signos en los cuales se encuentra una realidad representada y a la que le da su verdadero significado (Acosta, 2010). La cultura, contexto y experiencias del consumidor son clave para determinar la respuesta a productos. Los diseñadores de un producto dado están separados por un tiempo, lugar o grupo social. Por este motivo, el contexto de consumo dentro del cual el consumidor opera es una importante consideración, ya que es dentro de ese contexto que el mensaje de diseño es interpretado y desde el cual será influenciada la interpretación que lo origine (Crilly, Moultrie y Clarkson, 2004).

Para poder comprender el concepto de identidad es necesario conocer el concepto de cultura que refiere al conjunto de los rasgos distintivos, espirituales, materiales y afectivos que caracterizan una sociedad o grupo social. Además, ésta engloba artes, letras, modos de vida, creencias y tradiciones (Molano, 2007). En México, el interés por establecer un proceso de reconstrucción e identidad nacional empezó con los gobiernos post-revolucionarios, cuyos esfuerzos se centraron en las costumbres indígenas y las tradiciones (Mallet, 2010). La cultura nacional se ha entendido como un proceso dinámico e histórico que se transforma, incorporando nuevas necesidades y perspectivas, con la inclusión de los grupos étnicos, minorías nacionales y clases en sus diversas expresiones sociales (Puga, 1999). Moreno (2016) considera que la identidad mexicana se caracteriza por ser incompleta, fragmentada y diversificada. Para él, el mexicano es mestizo desde su nacimiento con tradiciones de grupos étnicos y de otros países. Así se puede decir que la nación mexicana es heterogénea, y que el proceso de mestizaje biológico y cultural ha sido en gran parte lo que la conforma (Giménez, 2012). Por ejemplo, una de las principales celebraciones es el día de muertos, que permite crear una interpretación del mundo en el cual México es único, culturalmente discreto y distinguible de su tradición española, o de la influencia norteamericana (Brandes, 1998).

\section{Marcas mexicanas que utilizan referentes mexicanos: investigación de campo}

Al hablar del tema de diseño gráfico mexicano sería impreciso hablar de este término como una categoría, ya que esto podría dar acepciones diversas, es decir, un diseño puede ser hecho en México, pero no por ello tendrá rasgos estéticos culturales del país, y por otra parte sería en el sentido justamente de contar con características o valores estéticos culturales como referente visual. Es por ello que cabe aclarar que para esta investigación se tomarán en cuenta a los productos hechos en México, hechos en México con referentes mexicanos y los extranjeros.

Con el fin de conocer y determinar el número de productos que utilizan gráficos basados en la cultura mexicana, se realizó una investigación con tres minoristas que cuentan con autoservicio de venta directo al público, estas fueron las tiendas: Grupo Sanborns Hermanos -Sanborns-, fundada por Walter Sanborn, farmacéutico de California, E.U.A. junto con su hermano Frank quienes inauguran Sanborn American Pharmacy, su primer tienda en el Centro de la Ciudad de México y actualmente cuentan con 166 tiendas por todo el 
territorio mexicano (Gsanborns, 2019). El puerto de Liverpool -Liverpool-, fundada por J.B. Ebrard en 1847 iniciando con un cajón dedicado a la venta de ropa en el centro de la Ciudad de México, hasta que en 1936 se inaugura la primer edificio y en 1962 su primer sucursal, actualmente gracias a la adquisición de Walmex -Suburbia-cuenta con 122 almacenes en México (El puerto de Liverpool, 2019). Y Soriana, empresa fundada en el año 1905 en la ciudad de Torreón, México, por don Pascual Borque, iniciando con la venta de telas a través de un mostrador, poco a poco el negocio fue creciendo y en 1920 ya vendía telas, ropa y novedades como perfumería y artículos para el hogar entre otros, actualmente y gracias a la adquisición de su competidor Gigante y la fusión con Comercial Mexicana, Soriana cuenta con 827 tiendas en diferentes formatos de negocio como Soriana Híper, Soriana Súper, Soriana Mercado, Bodega Comercial Mexicana, entre otros (Mercadosoriana, 2018). Para este estudio se seleccionó una sucursal de cada una de los minoristas a investigar: Sanborns, Liverpool y Soriana, de la ciudad de Guadalajara, México los meses de mayo y junio de 2019, para lo cual se hizo además, una selección de algunos departamentos para de ahí identificar los tipos de productos que se pretendían analizar. En el caso de Sanborns, se seleccionó sólo el departamento de Perfumes y maquillajes, que incluye los tipos de productos: Cosméticos, Tratamientos y Accesorios. En el caso de Liverpool, se observaron las marcas de cuatro departamentos de (1) Belleza, que incluye Maquillaje y Tratamientos; el departamento de (2) Accesorios; (3) departamento de Zapatos, enfocándonos a calzado para mujer y (4) departamento de Vinos y gourmet. En cuanto a Soriana, se trataron de seguir los mismos criterios de los departamentos de Liverpool, aunque los nombres de los departamentos cambian, los tipos de productos resultan muy similares: (1) departamento de Salud y belleza, analizando Cosméticos y Tratamientos; (2) departamento de Moda y accesorios; (3) departamento de Zapatos (mujer) y (4) departamento de Vinos y licores. En cuanto a los productos analizados se encontraron las siguientes cantidades de marcas: Sanborns: Cosméticos 28, Tratamientos 21 y Accesorios 16. Liverpool: Cosméticos 40, Tratamientos 12, Accesorios 12, Zapatos 55 y Vinos y gourmet 51 marcas. En el caso de Soriana: Cosméticos 13, Tratamientos 41, Moda y accesorios 13, Zapatos 3 y Vinos y licores 93 marcas. Estas cifras forman parte de los casos a analizar de los cuales encontramos marcas mexicanas y extranjeras, en donde en un primer acercamiento se procedió a enlistar las marcas de este estudio para posteriormente identificar el uso o no de elementos gráficos relacionados a la cultura mexicana.

Una vez definidas los puntos de venta, los departamentos, los tipos de productos y las marcas que serían utilizadas para este análisis, se procedió a identificar cuáles productos del universo definido se trataban de marcas mexicanas y cuáles de marcas extranjeras, para de ahí determinar cuántas hacen uso de referentes identitarios nacionales en el diseño de sus productos.

\section{Resultados de la investigación por canal}

En el caso de Sanborns se observó que en el único departamento estudiado, el de Perfumes y maquillaje en el área de Cosméticos el 79\% de las marcas son extranjeras (22), y de las 
marcas mexicanas encontradas, sólo una utiliza gráficos mexicanos. Se trata de Republic Cosmetics/Yuya, esta marca emplea una colección ilustrada por una diseñadora mexicana, donde cada gráfico se resaltan las raíces y cultura mexicana. El área de Tratamientos de la tienda Sanborns investigada, nos ofrece sólo un 29\% de marcas mexicanas, de las cuales ninguna presenta uso o intervención de la cultura mexicana. Y en el caso de los Accesorios, solamente una marca mexicana de las tres identificadas compite contra una abrumadora mayoría de productos extranjeros (75\%). Se trata de la marca Corazón de Melón, que presenta una marca original y fresca que plasma sus raíces multiculturales con texturas, colores, materiales contrastantes para hacer distintivo cada uno de sus diseños. En general el estudio de estas marcas en Sanborns nos revela que el 75\% de marcas son extranjeras y del resto, es decir, marcas mexicanas sólo el 3\% utiliza elementos relacionados a la gráfica y cultura identitaria de México.

\begin{tabular}{|l|l|l|l|c|c|c|}
\hline $\begin{array}{l}\text { Cadena } \\
\text { comercial }\end{array}$ & Departamento & $\begin{array}{l}\text { Tipo de } \\
\text { producto }\end{array}$ & $\begin{array}{l}\text { Marcas } \\
\text { mexicanas } \\
\text { con gráficos } \\
\text { mexicanos }\end{array}$ & $\begin{array}{l}\text { Marcas } \\
\text { mexicanas } \\
\text { sin gráficos } \\
\text { mexicanos }\end{array}$ & $\begin{array}{l}\text { Marcas } \\
\text { extranjeras }\end{array}$ & $\begin{array}{l}\text { Número } \\
\text { de } \\
\text { marcas } \\
\text { presentes }\end{array}$ \\
\hline Sanborns & $\begin{array}{l}\text { Perfumes y } \\
\text { maquillaje }\end{array}$ & Cosméticos & 1 & 5 & 22 & 28 \\
\hline Sanborns & $\begin{array}{l}\text { Perfumes y } \\
\text { maquillaje }\end{array}$ & Tratamientos & 0 & 6 & 15 & 21 \\
\hline Sanborns & $\begin{array}{l}\text { Perfumes y } \\
\text { maquillaje }\end{array}$ & Accesorios & 1 & 3 & 12 & 16 \\
\hline Total & & & 2 & 14 & 49 & 65 \\
\hline
\end{tabular}

Tabla 2. Marcas analizadas en Sanborns. Fuente: (Mora, Orozco-Grover y Santoyo, 2019, s/p).

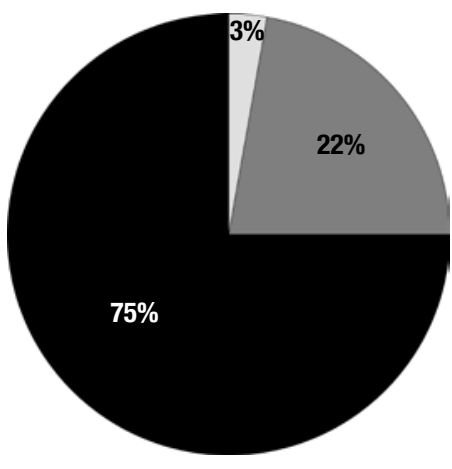

Marcas mexicanas con gráficos mexicanos

Marcas mexicanas sin gráficos mexicanos

Marcas extranjeras

Figura 3. Análisis de marcas en todos los departamentos de Sanborns (Mora, OrozcoGrover y Santoyo, 2019, s/p). 
Por su parte Liverpool, de las marcas analizadas en el área de Cosméticos cuenta con 90\% de marcas extranjeras y $10 \%$ mexicanas, de las cuales la totalidad (4) cuenta con gráficos mexicanos. Estas marcas son Republic Cosmetics/Yuya, Ahal, Pai Pai y Handlab. Estas marcas representan las tradiciones, cultura y arte mexicano por medio de imágenes de reconocidos ilustradores plasmadas en sus productos. Caso contrario en el área de Tratamientos, que nos muestra 92\% marcas extranjeras, $8 \%$ mexicanas, con ninguna intervención gráfica. En cuanto a las marcas de Accesorios, Liverpool nos ofrece $75 \%$ de marcas mexicanas y en su mayoría (9) utilizan gráficos relacionados a la cultura mexicana, en donde podemos observar que la identidad corporativa continúa este hilo conductor de combinaciones de colores, patrones de símbolos, en el diseño del producto, pasando a formas más abstractas, pero reconocibles. Estas marcas son: Corazón De Melón, Ohja, Lorena Saravia, Mildred, Rubin Sister by PM, Kris Goyri, Parallet, Alejandro Carlín y Angelozano.

Las marcas de zapatos para dama que encontramos en Liverpool son en su mayoría extranjeras (73\%), sin embargo, nueve de las quince marcas mexicanas hacen uso de elementos identitarios mexicanos en su diseño. Cloe, Westies, Angelozano, Guraparra, Lyard, Manet, Peyotl, Ramiro Olivares y Calzado Efe construyen una identidad visual a partir del logotipo, símbolos, colores corporativos y tipografía, donde se mantienen los diferentes tonos de voz, con un enfoque en el usuario como personaje principal de cada marca.

Con respecto al departamento de Vinos y gourmet, la totalidad de marcas mexicanas hacen uso de gráficos mexicanos, es decir quince (29\%) de las 51 marcas analizadas. Tierra Adentro, La Cetto, La Redonda, La Trinidad, Monte Xanic, Encinillas, Norte 32, Quinta Monasterio, Santo Tomás, Laberinto, MonteFiori, El Cielo, De Cote, Casa Madero y Retorno cuentan con un sistema de diseño que reacciona al contexto, relacionando la importancia y el concepto del origen del producto.

Si bien el 73\% de las marcas analizadas en este punto de venta son extranjeras, vemos otra propuesta con respecto al primer minorista ya que el $21 \%$ de las marcas analizadas en Liverpool están inspiradas en la gráfica mexicana.

\begin{tabular}{|l|l|l|l|l|l|l|}
\hline $\begin{array}{l}\text { Cadena } \\
\text { comercial }\end{array}$ & Departamento & $\begin{array}{l}\text { Tipo de } \\
\text { producto }\end{array}$ & $\begin{array}{l}\text { Marcas } \\
\text { mexicanas } \\
\text { con gráficos } \\
\text { mexicanos }\end{array}$ & $\begin{array}{l}\text { Marcas } \\
\text { mexicanas } \\
\text { sin gráficos } \\
\text { mexicanos }\end{array}$ & $\begin{array}{l}\text { Marcas } \\
\text { extranjeras }\end{array}$ & $\begin{array}{l}\text { Número } \\
\text { de } \\
\text { marcas } \\
\text { presentes }\end{array}$ \\
\hline Liverpool & Belleza & Cosméticos & 4 & 0 & 36 & 40 \\
\hline Liverpool & Belleza & Tratamientos & 0 & 1 & 11 & 12 \\
\hline Liverpool & $\begin{array}{l}\text { Accesorios } \\
\text { (Mujer) }\end{array}$ & $\begin{array}{l}\text { Accesorios } \\
\text { (Mujer) }\end{array}$ & 9 & 3 & 4 & 16 \\
\hline Liverpool & $\begin{array}{l}\text { Zapatos } \\
\text { (Mujer) }\end{array}$ & $\begin{array}{l}\text { Zapatos } \\
\text { (Mujer) }\end{array}$ & 9 & 6 & 40 & 55 \\
\hline
\end{tabular}

continúa $>>$ 


\begin{tabular}{|l|l|l|l|l|l|l|}
\hline Liverpool & $\begin{array}{l}\text { Vinos y } \\
\text { Gourmet }\end{array}$ & $\begin{array}{l}\text { Vinos y } \\
\text { Gourmet }\end{array}$ & 15 & 0 & 36 & 51 \\
\hline Total & & & 37 & 10 & 127 & 174 \\
\hline
\end{tabular}

Tabla 3. Marcas analizadas en Liverpool. Fuente: (Mora, Orozco-Grover y Santoyo, 2019, s/p).

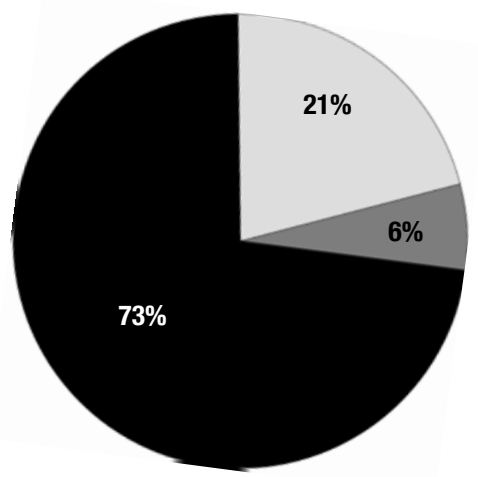

Marcas mexicanas con gráficos mexicanos

Marcas mexicanas sin gráficos mexicanos

Marcas extranjeras

Figura 4. Análisis de marcas en todos los departamentos de Liverpool (Mora, OrozcoGrover y Santoyo, 219, s/p).

El caso de Soriana se tiene que analizar con mesura, ya que al observar los números globales vemos que de los 163 productos analizados sólo hay un 49\% de marcas extranjeras y que del resto, el $32 \%$ cuenta con gráficos mexicanos, es decir 52 marcas. Lo que hay que analizar con cuidado es que 49 de esas 52 marcas corresponden a Vinos y licores, es decir, del resto de las categorías sólo tres hacen uso de elementos identitarios de México, esos tres son de Accesorios de mujer. Lo que significa que de los departamentos de Cosméticos, Tratamientos y Zapatos no se encontró ninguna marca con elementos relacionados a la cultura nacional, aunque existen marcas mexicanas en ellos. Cosméticos $69 \%$ extranjeros, $31 \%$ nacional. Tratamientos $41 \%$ extranjeros, 59\% nacional. Y Zapatos $67 \%$ extranjeros, $33 \%$ nacional. En todos los casos reportan cero marcas con gráficos mexicanos.

En el caso de Moda y accesorios como se comentó anteriormente, existen tres marcas (23\%) de las trece encontradas que emplean gráficos mexicanos, el resto $62 \%$ extranjeras y 15\% mexicanas pero que no incluyen elementos culturales. Esas marcas son Ilusión, Vassarette y Berlei que presentan prendas de uso interior confeccionadas a partir de telas y patrones inspirados en la comodidad y la versatilidad, el diseño fusiona la suavidad y limpieza de los cortes simples, con toques rudos en colores y algunos materiales. El departamento de Vinos y licores de Soriana presenta un caso especial, en donde encontramos un 53\% de productos mexicanos y todos hacen uso de referentes identitarios de México. Marcas como Cucapa, Brown, Insurgente, Victoria, Corona, León, El recuerdo de Oaxaca, 
Antiguo de Herradura, Espolón y Mezcal amores son algunas de los 49 marcas relacionadas con la herencia visual mexicana. Estas marcas y su identidad visual están inspirados en distintos emblemas mexicanos, típicos del país, que aluden a la sencillez y la fuerza del color, y la tipografía enfatizada por los gráficos característicos las marcas.

\begin{tabular}{|l|l|l|l|l|l|l|}
\hline $\begin{array}{l}\text { Cadena } \\
\text { comercial }\end{array}$ & Departamento & $\begin{array}{l}\text { Tipo de } \\
\text { producto }\end{array}$ & $\begin{array}{l}\text { Marcas } \\
\text { mexicanas } \\
\text { con gráficos } \\
\text { mexicanos }\end{array}$ & $\begin{array}{l}\text { Marcas } \\
\text { mexicanas } \\
\text { sin gráficos } \\
\text { mexicanos }\end{array}$ & $\begin{array}{l}\text { Marcas } \\
\text { extranjeras }\end{array}$ & $\begin{array}{l}\text { Número } \\
\text { de marcas } \\
\text { presentes }\end{array}$ \\
\hline Soriana & $\begin{array}{l}\text { Salud y } \\
\text { belleza }\end{array}$ & $\begin{array}{l}\text { Cosméticos } \\
\text { (13) }\end{array}$ & 0 & 4 & 9 & 13 \\
\hline Soriana & $\begin{array}{l}\text { Salud y } \\
\text { belleza }\end{array}$ & $\begin{array}{l}\text { Tratamientos } \\
(41)\end{array}$ & 0 & 24 & 17 & 41 \\
\hline Soriana & $\begin{array}{l}\text { Moda y } \\
\text { accesorios } \\
\text { (Mujer) }\end{array}$ & $\begin{array}{l}\text { Moda y } \\
\text { accesorios } \\
\text { (Mujer) (13) }\end{array}$ & 3 & 2 & 8 & 13 \\
\hline Soriana & $\begin{array}{l}\text { Zapatos } \\
\text { (Mujer) }\end{array}$ & $\begin{array}{l}\text { Zapatos } \\
\text { (Mujer) }\end{array}$ & 0 & 1 & 2 & 3 \\
\hline Licoses & $\begin{array}{l}\text { Vinos y } \\
\text { Gourmet } \\
\text { (93) }\end{array}$ & 49 & 0 & 44 & 93 \\
\hline
\end{tabular}

Tabla 4. Marcas analizadas en Soriana. Fuente: (Mora, Orozco-Grover y Santoyo, 2019, s/p).

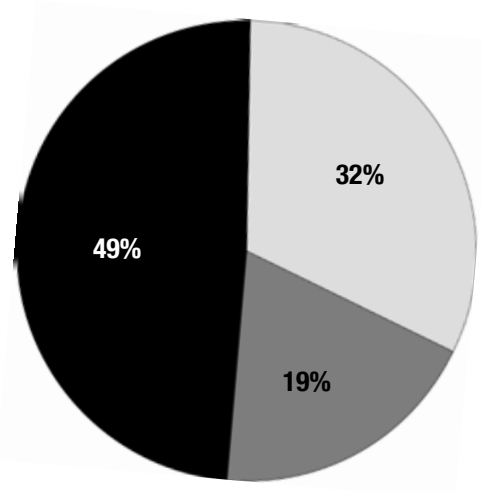

Marcas mexicanas con gráficos mexicanos

Marcas mexicanas sin gráficos mexicanos

Marcas extranjeras

Figura 5. Análisis de marcas en todos los departamentos de Soriana (Mora, OrozcoGrover y Santoyo, 2019, s/p). 


\section{Resultados de la investigación por categoría de producto}

Para la presente investigación se seleccionaron cinco departamentos de productos de consumo con la intención de identificar el uso y determinar el valor o menosprecio de los responsables del diseño de envases, marketing y comunicación de la totalidad de marcas encontradas en tres de los principales canales de distribución en México. Este proceso de observación nos permite determinar la estrategia de imagen de las marcas encontradas en las siguientes categorías antes mencionadas: Cosméticos, Tratamientos de belleza, Accesorios para mujer, Zapatos para dama y otra categoría para Vinos, licores y gourmet.

A partir del análisis de los datos obtenidos se observa que el departamento en donde más marcas hacen uso de referentes de la cultura mexicana en sus piezas gráficas es el de Vinos y licores, ya que de las 144 marcas encontradas el 44\% incluye dichos referentes, entre los productos investigados se sobresalen licores y destilados, licores y cremas, whiskies, brandies, rones, tequilas, mezcales, vodkas, ginebras y cognacs.

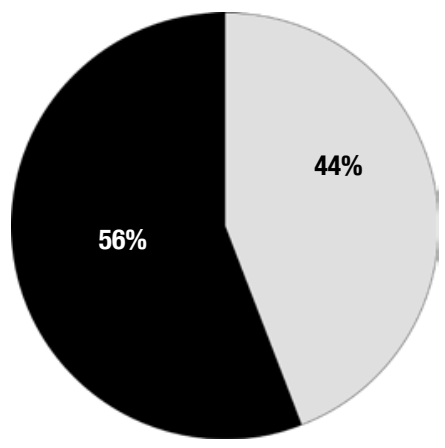

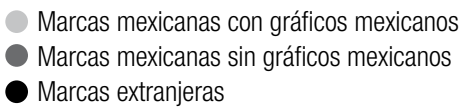

Figura 6. Análisis de marcas de Vinos y licores (Mora, Orozco-Grover y Santoyo,2019, s/p).

En segundo lugar de las 57 marcas observadas en el departamento de Accesorios se encontró que el $23 \%$ usan gráficos mexicanos, entre los que se encuentran ropa, bolsos, carteras, bodies y control, ropa interior, relojes, joyería, collares, aretes, pulseras, anillos y cinturones.

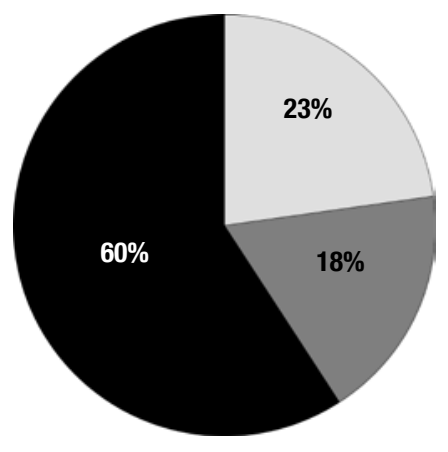

Figura 7. Análisis de marcas de Accesorios (Mora, Orozco-Grover y Santoyo, 2019, s/p). 
En tercer lugar vemos que de las 58 marcas de zapatos analizadas, el 16\% de las ellas hacen uso de elementos inspirados en la cultura mexicana, entre los que destacan tenis/sneakers -zapatillas-, sandalias - playera-, zapatos de tacón, zapatos de plataforma, botas y botines, confort y deportivos.

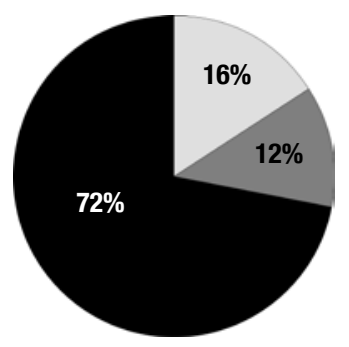

Marcas mexicanas con gráficos mexicanos

Marcas mexicanas sin gráficos mexicanos

Marcas extranjeras

Figura 8. Análisis de marcas de Zapatos (Mora, Orozco-Grover y Santoyo, 2019, s/p).

De las 81 marcas de Cosméticos encontradas, se concluye que este es uno de los departamentos que menos toman en cuenta gráficos culturales, ya que sólo el $6 \%$ los valoran. En este categoría se incluyen polvos, correctores, blush, lipsticks, sombras, productos para cejas, máscara de pestañas, brochas, esmaltes de uñas, delineador de ojos, entre otros.

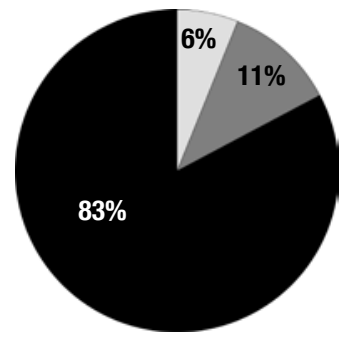

Marcas mexicanas con gráficos mexicanos
Marcas mexicanas sin gráficos mexicanos
Marcas extranjeras

Figura 9. Análisis de marcas de Cosméticos (Mora, Orozco-Grover y Santoyo, 2019, s/p).

Y por último en el departamento de Tratamientos, ninguna de las 74 marcas demuestra una importancia hacia el recurso gráfico mexicano. Productos como desmaquillantes, productos para el cuidado de la piel, del cabello, etcétera, arrojan un $0 \%$ de aprecio a referentes de la cultura nacional.

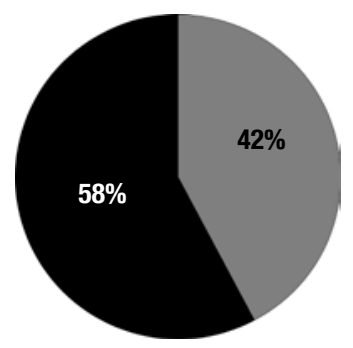

Marcas mexicanas con gráficos mexicanos

Marcas mexicanas sin gráficos mexicanos

Marcas extranjeras

Figura 10. Análisis de marcas de Tratamientos (Mora, Orozco-Grover y Santoyo, 2019, s/p). 


\section{Resultados del análisis comparativo}

Casos como la marca de cosméticos Republic Cosmetics/Yuya demuestran que cuentan con una estrategia creativa centrada en temas populares de la cultura mexicana, lo que crea un vínculo natural y accesible para el usuario. Corazón de Melón, al usar elementos mexicanos persigue el objetivo principal de la marca que es centrar su diseños en la expresión y versatilidad. Los productos cosméticos que presentan gráficos mexicanos transmiten un aspecto integral y una sensación de homogeneidad de acuerdo con los valores de la marca. Las marcas de accesorios exploran la posibilidad de crear una línea de productos en la gama de la moda donde se experimenta con el diseño de sus empaques y logotipos, denotando un tono fresco lleno de tradición y pasión. Observsamos que las marcas de calzado además de cuidar sus procesos de fabricación artesanales, otro de sus focos es la innovación en sus diseños. Las marcas de vinos y licores trabajan con un tono de voz directo, claro y cercano, que establece un diálogo fluido entre la marca y los usuarios. El equilibrio entre rigor y calidez son clave para su mensaje, lo que genera un vínculo entre el pasado de México y su modernidad a través de su diseño.

De los datos obtenidos cabe aclarar que de las 414 marcas encontradas, algunas de ellas se repiten ya que se encontraron en dos de los tres canales investigados, para fines prácticos se tomaron como dos casos diferentes, para poder identificar los totales de marcas extranjeras y marcas mexicanas, entre las que diferenciamos las que sí y las que no hacen uso de gráficos mexicanos. En resumen se puede concluir que casi dos terceras partes (64\%) de las marcas son extranjeras (266), provenientes de países como Estados Unidos, Francia, España, entre otros, $14 \%$ son marcas mexicanas que no usan gráficos mexicanos (57) y el $22 \%$ del total de marcas investigadas sí los usan (91 marcas). Lo que quiere decir que de las 148 marcas nacionales encontradas el 61.5\% usan referentes emanados de la cultura mexicana.

\begin{tabular}{|l|l|l|l|l|l|l|}
\hline & Cosméticos & Tratamientos & Accesorios & Zapatos & $\begin{array}{l}\text { Vinos y } \\
\text { licores }\end{array}$ & Total \\
\hline $\begin{array}{l}\text { Marcas mexicanas } \\
\text { con gráficos } \\
\text { mexicanos }\end{array}$ & 5 & 0 & 13 & 9 & 64 & 91 \\
\hline $\begin{array}{l}\text { Marcas mexicanas } \\
\text { sin gráficos } \\
\text { mexicanos }\end{array}$ & 9 & 31 & 10 & 7 & 0 & 57 \\
\hline Marcas extranjeras & 67 & 43 & 34 & 42 & 80 & 266 \\
\hline $\begin{array}{l}\text { Número de marcas } \\
\text { presentes }\end{array}$ & 81 & 74 & 57 & 58 & 144 & 414 \\
\hline
\end{tabular}

Tabla 5. Marcas encontradas en la investigación. Fuente: (Mora, Orozco-Grover y Santoyo, 2019, s/p). 


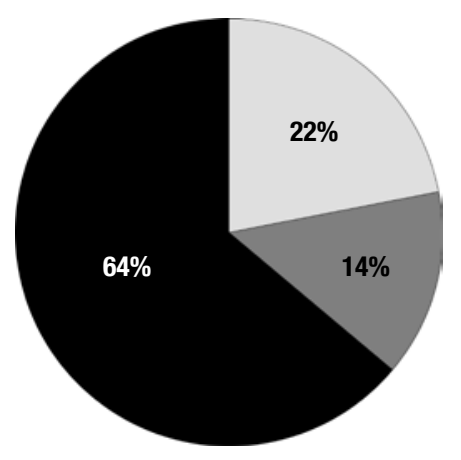

Marcas mexicanas con gráficos mexicanos

Marcas mexicanas sin gráficos mexicanos

- Marcas extranjeras

Figura 11. Análisis de todas las marcas encontradas (Mora, Orozco-Grover y Santoyo, 2019, s/p).

\section{Marcas nacionales dirigidas al mercado nacional}

Existen varios casos de marcas mexicanas de productos hechos en México que utilizan valores estéticos en sus productos o diseño de piezas, sin embargo en relación a la gráfica de su marca o identidad no son muy representativas de estos valores, algunas de ellas son: Merakia, Thalatha y Txt.ure, reseñadas por López (2019) mismas que exponemos brevemente a continuación.

La marca Merakia crea objetos utilitarios, fusionando técnicas y materiales tradicionales y actuales y como resultado de su trabajo se pueden observar piezas que van desde una serie de tortilleros, difusores, botellas y lámparas, los cuales fueron inspirados en distintos emblemas mexicanos y realizados en materiales típicos de nuestro país.

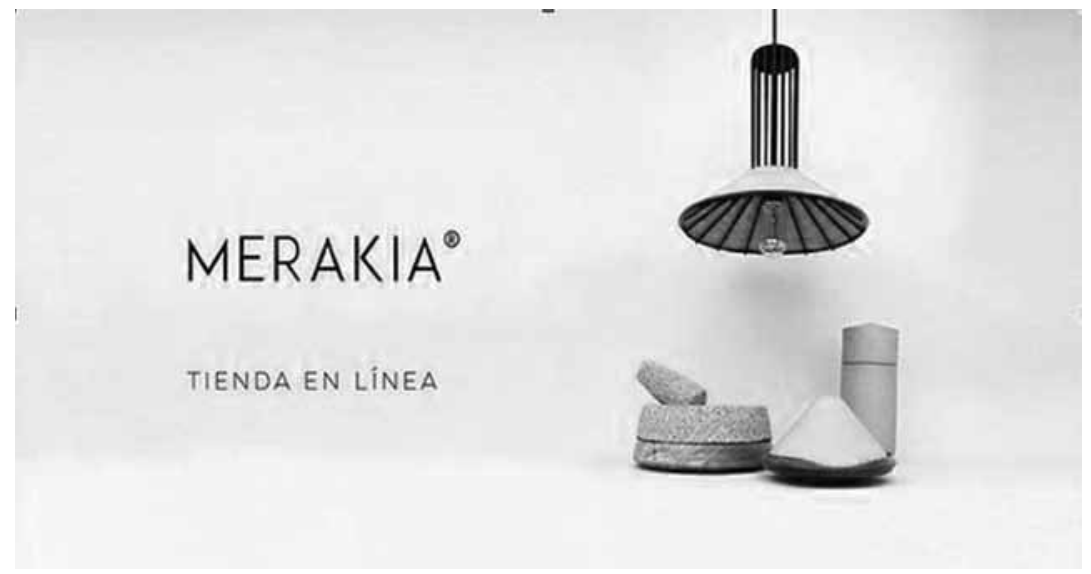

Figura 12. Publicidad de productos marca Merakia (https://www.merakia.com.mx, 2019, s/p). 
Thalatha es un proyecto de joyería artesanal, basado en conceptos de la energía universal y la naturaleza, que en conjunto con lo mejor de los insumos y técnicas artesanales mexicanos explotan a través de piezas principalmente minimalistas, basado en referencias místicas en el diseño.

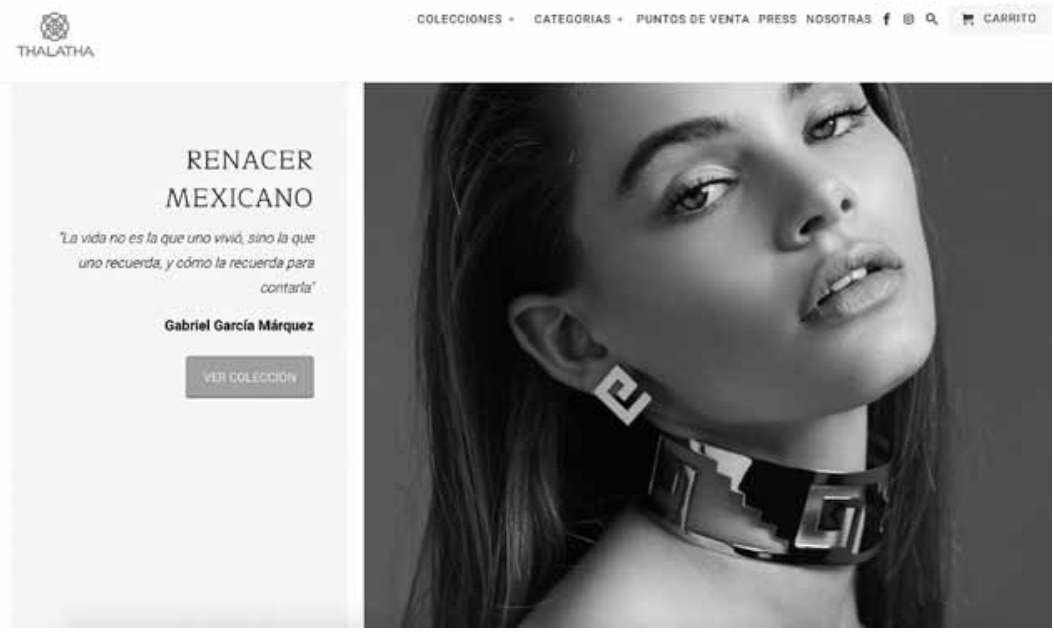

Figura 13. Publicidad de marca de productos Thalatha (https://thalatha.mx, 2019, s/p).

Txt.ure, es una firma que se dedica a la preservación de técnicas artesanales de diseño, siendo su idea el generar un vínculo entre el pasado de México y su modernidad a través de objetos de decoración creados con insumos nacionales.

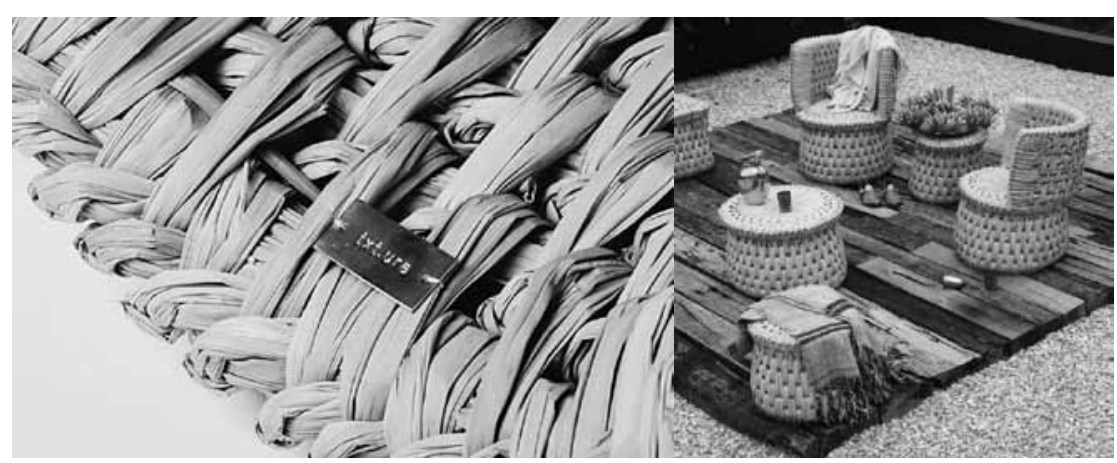

Figura 14. Muestra de productos de la marca Txt.ure ( http://www.txt-ure.mx, 2019, s/p). 
Por otra parte, existen otro tipos de productos que en su identidad de marca utilizan recursos y valores estéticos basados en conceptos de la cultura mexicana, uno de estos casos es la marca Pai pai, representa en su identidad gráfica las tradiciones, cultura y arte mexicano a través de imágenes de reconocidos ilustradores plasmadas en sus labiales. La construcción fonética de la marca, Pai Pai, proviene de un grupo indígena de Baja California y su significado es «Gente viva, Gente que se mueve». En sus características destaca lo genuino de sus colecciones pues ninguna colección es igual a otra, los artistas plásticos y los colores cambian cada temporada, saliendo de los estándares típicos del mundo de la belleza, con gamas de colores innovadoras, que van desde el tono rosa horchata hasta un color ponche.
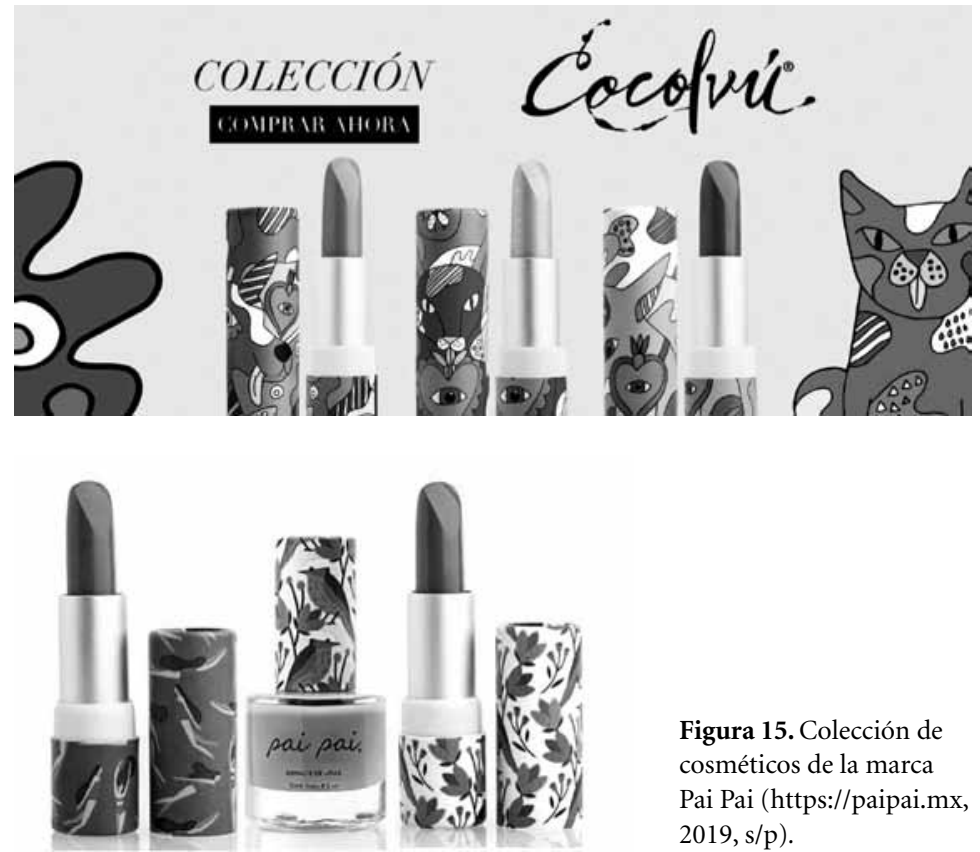

Figura 15. Colección de cosméticos de la marca Pai Pai (https://paipai.mx, 2019, s/p).

Otros casos como este, en el que la imagen del producto y la identidad de marca exploran y explotan recursos culturales con un valor estético para aplicarlos como recurso visual y que han tenido mucho éxito, son los casos de las marcas Pineda Covalini y Takasami, marcas enfocadas a productos de alta gama. 
La marca Pineda Covalini creada en 1996 por diseñadores mexicanos, que entre sus productos ofrece mascadas de seda, vestidos, carteras, joyería, chamarras, entre otros, afirma que ha fomentado la riqueza cultural de nuestro país a través de sus diseños plasmados en seda, mostrándola mundialmente de una forma vanguardista y exclusiva.

Representa la transmutación de las antiguas expresiones culturales asomadas a la vida moderna de nuestro país. Es el valioso testimonio de nuestra cultura popular mirándose en el espejo del mundo. Es una invitación a viajar por los caminos de un México que mira al mundo moderno a través de los ojos de su historia, de sus tradiciones, de su pluralidad cultural, de su multiplicidad étnica y de su fértil imaginación. Y es, también, un merecido homenaje a los creadores anónimos de todos los tiempos que plasmaron la cosmogonía de México en los fantásticos diseños que hoy en día, como símbolos, representan lo que somos como Nación (https://pinedacovalin.com/pages/acerca-denosotros, 2019, s/p.).

Algo importante de mencionar acerca de esta marca es que, sus diseños son una reinterpretación libre. En caso de ser producto de una colaboración especial, cuenta con el debido contrato, derechos de reproducción y uso por parte del ó los artistas titulares del diseño; además se otorga el crédito a las instituciones especialistas en la materia tales como el INAH y el museo correspondiente en su caso.
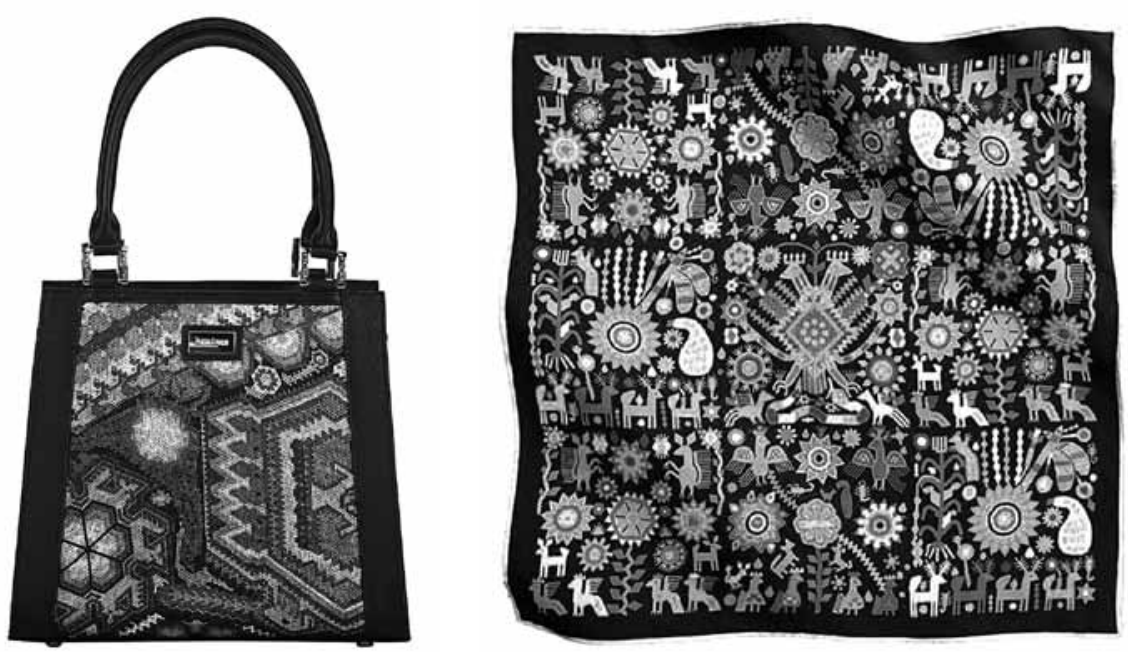

Figura 16. Productos de la marca Pineda Covalin. Bolso Yaab Chaquira y mascada Espíritu Huichol (https://pinedacovalin.com, 2019). 
Por otra parte y en relación a esta alta gama, se encuentra el caso de la marca de diseñador Takasami. La marca TAKASAMI, reconocida a nivel nacional e internacional por su compromiso social con las artesanas mexicanas, consolidada exitosamente por María Rosario Mendoza fue galardonada por UNICEF con el Women's Together Award en la sede la ONU en Nueva York 2017. Primera marca de moda mexicana premiada por decisión unánime con un EMMY por parte de la Academia de Televisión, Artes y Ciencias de EUA, por el diseño de vestuario de la ceremonia de inauguración y clausura de los Juegos Panamericanos 2011.
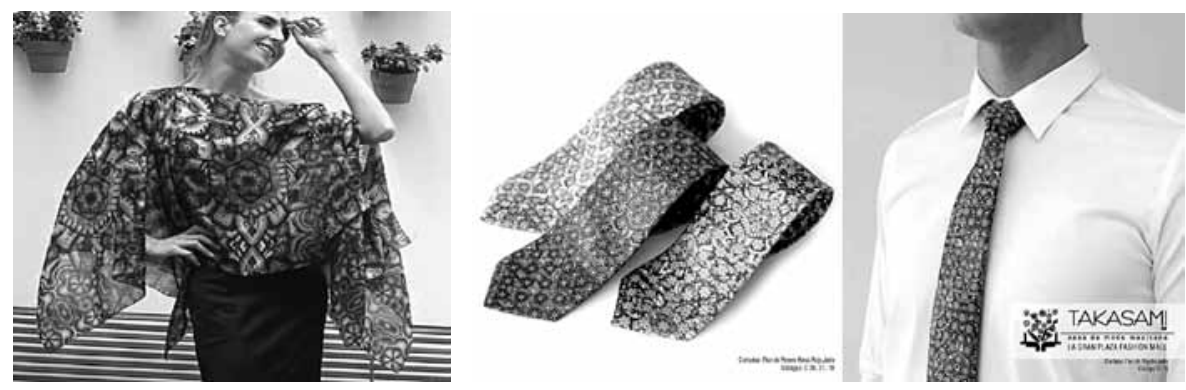

Figura 17. Productos de la marca Takasami. Corbata Arte Huichol, inspirada en el peyote, cactácea ritual y sagrada que les da poder e iluminación y blusón Arte Huichol, inspirado en la visión cósmica de la cultura Wixárika (https://takasami.com, 2019.).

Ambos casos, como puede evidenciarse en los productos mostrados, aplican tramas o texturas visuales tomando como inspiración aspectos culturales de grupos indígenas. De esta manera, la apariencia que guardan los objetos diseñados y el cuidado en el trabajo de cada uno de ellos provocan la gran aceptación que han tenido en el consumidor.

La apariencia visual de los productos es crucial al determinar la respuesta del consumidor y el éxito del producto. Los clientes valoran dichos productos principalmente considerando su elegancia, funcionalidad y significado social, como atributos percibidos y frecuentemente asociados a la satisfacción de deseos del cliente, más que a sus necesidades (Crilly, Moultrie y Clarkson, 2004). De esta manera, en el diseño de productos se considera que las relaciones cliente-producto se manifiestan en el entendimiento de la identidad cultural por medio de aspectos simbólicos y semánticos (Padilla, 2014). En el diseño, el uso de la cultura como identidad enriquece la interacción entre el producto y el usuario (Chen, 2011). 


\section{Conclusiones generales}

Tras un recorrido por algunos referentes de la identidad cultural mexicana, potenciada por su riqueza étnica, podemos advertir que ésta pudiera ser considerada como una útil y vasta fuente de inspiración para la generación de conceptos y gráfica para productos hechos en México. Sin embargo, el empleo de dichos valores simbólicos y visuales en la construcción de piezas de comunicación para productos y servicios de origen mexicano no es algo que se pueda observar con frecuencia.

En la presente investigación sobre la inclusión de referentes mexicanos en productos de consumo habitual, se evidencia claramente que es un mínimo porcentaje de productos mexicano que aplican el diseño gráfico tomando en cuenta referentes culturales del país, logrando observar que el uso de dichos recursos se utiliza principalmente en productos como vinos y licores, además de vestimenta y accesorios alta gama. Un análisis comparativo llevado a cabo en tres de los principales almacenes y autoservicios del país da cuenta de ello.

La diversidad, riqueza y recursos con los que la cultura mexicana cuenta son de gran valor, no solo cultural sino también estético y gráfico, mismos que pudieran enriquecer en muchos casos a la comunicación y conceptualización de la gran diversidad de productos de consumo, siendo en muchas ocasiones productos típicos del país o regiones que podrían proyectar una mayor identidad y relación con su giro comercial.

No obstante, el éxito comercial que representan los productos y accesorios de gama alta que sí hacen uso de dichos referentes pudiera ser considerado como un aliciente para que -por imitación o siguiendo el ejemplo, otras marcas en diversos giros y estratos, puedan considerar el aporte que la estética empleada hace a la comercialización de dichos productos y servicios. Si bien el éxito comercial de las marcas expuestas no se debe únicamente a la imagen gráfica y de producto que éstas poseen, sí logran consolidar y dotarles de un carácter distintivo, diferenciador y de calidad que los posiciona por encima de sus competidores.

Aunque en la actualidad son pocos los casos en los que este potencial se explota en el diseño de piezas que habrán de distribuirse de manera cotidiana en el territorio nacional mexicano, su análisis y estudio permite ahondar en la correlación que existe entre la creación de valor y el empleo de elementos distintivos de la identidad cultural mexicana, permitiendo a su vez compartir a las nuevas generaciones de diseñadores gráficos la posibilidad de enriquecer su labor profesional al potenciar sus diseños con el empleo de elementos identitarios de alto valor simbólico, histórico y comunicacional.

\section{Referencias Bibliográficas}

Acosta, B. (2010). Signos, símbolos y rituales en la construcción. Recuperado de: http://lsocial. udistrital.edu.co:8080/documents/37512/43300/(05)+Bernardo+Acosta+Martinez.pdf

Brandes, S. (1998). The day of the dead, halloween, and the quest for mexican national identity. The Journal of American Folklore, 111(442), 359-380. 
Chen, S.-J. (2011) en Aguilar, F., De la Torre, A. y Martel, S. (2019). Análisis de la identidad mexicana en el diseño de mobiliario en México. Vol. VIII, (19). Recuperado de: http:// www.espacioimasd.unach.mx/articulos/vol.8/19/art3.php (fecha de consulta: 27 de junio de 2019).

Chihu, A. (2002). Sociología de la identidad. UAM-Ixtapaluca. México.

Cisneros, S. (23 de junio 2019). "20 pueblos y grupos indígenas de México con mayor población”. Recuperado de: https://www.mexicodesconocido.com.mx/pueblos-indigenasen-mexico.html.

Crilly, N., Moultrie, J. y Clarkson, P. J. (2004). “Seeing things: consumer response to the visual domain in product design”. Design Studies, 25(6), 547-577. doi:10.1016/j.destud. 2004.03.001

Cuche, D. y Mahler, P. (1999). La noción de cultura en las ciencias sociales. Buenos Aires: Ediciones Nueva Visión.

Elpuertodeliverpool. (2 de agosto de 2019). "Historia. Recuperado de: https://www.elpuerto deliverpool.mx/historia.html

Giménez, G. (2002). Paradigmas de identidad. Sociología de la identidad. UAM-Ixtapalapa, Miguel Ángel Porrúa, México. 412 p.

Giménez, G. (2012). La cultura como identidad y la identidad como cultura. Recuperado de: http://perio.unlp.edu.ar/teorias2/textos/articulos/gimenez.pdf

González-Varas, I. (1999). Conservación de bienes culturales: teoría, historia, principios y normas.

Gsanborns. (2 de agosto de 2019). "Historia”. Recuperado de: http://www.gsanborns.com. $\mathrm{mx} /$ historia.html

Ibero 90.9 (13 de agosto de 2019). Consulta sobre reforma para pueblos indígenas y afromexicano. Recuperado de: https://ibero909.fm/radar-con-mario-campos/consultasobre-reforma-para-pueblos-indgenas-y-afromexicano.

Koc, M. (1994). "La globalización como discurso". En Globalización del sector agrícola y alimentario. (pp. 51-78). Ministerio de Agricultura, Alimentación y Medio Ambiente.

López, F. (20 de Mayo de 2019). "10 marcas mexicanas independientes de diseño que debes conocer”. Travesiasdigital.com. Recuperado de: https://travesiasdigital.com/noticias/ marcas-mexicanas-independientes-diseno.

Mallet, A. (2010). Clara Porset diseño e identidad. Recuperado de: http://cral.in2p3.fr/ artelogie/IMG/article_PDF/article_a228.pdf

Manríquez Durán, M. y Castro Silva, T. (2007). Globalización y diversidad cultural en el Sonora contemporáneo: Variaciones sobre región, etnia y lenguaje. Región y sociedad, 19(SPE), 219-235.

Merakia (2019). Merakia objetos utilitarios de diseño mexicano. Consultado el 18 de Julio 2019. Recuperado de: https://www.merakia.com.mx

Mercadosoriana (2 de agosto de 2019). "Nuestra historia”. Recuperado de: http://www. mercadosoriana.com/site/default.aspx? $\mathrm{p}=2946$

Milenio (13 de agosto de 2019). “Conoce las 68 lenguas indígenas de México”. Recuperado de: https://www.milenio.com/cultura/conoce-las-68-lenguas-indigenas-de-mexico.

Molano, L. (7 de mayo de 2007). Identidad cultural un concepto que evoluciona. Recuperado de: http://www.redalyc.org/pdf/675/67500705.pdf 
Moreno, M. (10 de mayo de 2016). Identidad mexicana. Recuperado de: http://www.iest. edu.mx/revista-humanidades/identidad-mexicana

Moya, R. (2006). Latin American Graphic Design, diseño gráfico latinoamericano. Ediciones Trama. Ecuador.

Pai Pai (2019). Página principal. Consultado el 18 de Julio de 2019 en https://paipai.mx

Pineda, C. (2019). “Acerca de nosotros. Pineda Covalin". Consultado el 18 de Julio de 2019 en https://pinedacovalin.com/pages/acerca-de-nosotros

Puga, C. (1999). Hacia la sociología. México: Pearson.

Rentería, M. Á. S. (2005). "Identidad étnica y la relación de los pueblos indígenas con el Estado mexicano". Ra Ximhai: revista científica de sociedad, cultura y desarrollo sostenible, $1(2), 239-260$.

Takasami (18 Julio 2019). Nosotros. https://takasami.com.mx/. Recuperado de: https:// takasami.com.mx/pages/nosotros

Thalatha (18 de Julio 2019). Página inicio. Recuperado de: https://thalatha.mx

UNESCO (26 de junio 2019): Glosario | Organización de las Naciones Unidas para la Educación, la Ciencia y la Cultura. Unesco.org. Recuperado de: http://www.unesco.org/new/ es/culture/themes/cultural-diversity/cultural-expressions/programmes/global-alliancefor-cultural-diversity/resource-centre/tools/glossary/.

\begin{abstract}
The Mexican cultural identity, with its pre-Hispanic values and ethnic wealth, is a vast source of conceptual, symbolic and visual references for the construction of communication pieces, graphic identity and packaging design for products and services of national origin, however, this resource is usually taken advantage of only when it is oriented towards the tourism sector, since its use in consumer products is usually considered to be of lower value or quality by the consumer. This analysis aims to highlight this situation, as well as to contrast the creative and commercial potential that can be derived from the use of national identity references in package design and communication. At present there are few cases in which this potential is exploited in the design of pieces that will be distributed on a daily basis in the Mexican national territory, being the most common to find goods that replicate visually and conceptually various graphic tendencies emanated or used in the North American market, having an impact on a limited and sporadic creation of value through brands with Mexican cultural identity, diluting the possibility of endowing them with a high symbolic, historical and communicational value.
\end{abstract}

Keywords: Mexican identity - Packaging design - National design - Made in Mexico - Prehispanic references.

Resumo: A identidade cultural mexicana, com os seus valores prehispánicos e riqueza étnica, são uma vasta fonte de referências conceptuais, simbólicas e visuais para a construção de peças de comunicação, identidade gráfica e desenho de recipientes para produtos e serviços de origem nacional, contudo, este recurso só, normalmente, é aproveitado 
quando se orienta ao setor turístico, ja que o seu uso em produtos de consumo diário no mercado mexicano costuma ser considerado como de menor valor ou qualidade por parte do consumidor. Esta análise pretende evidenciar esta situação , assim como contrastar o potencial creativo e comercial que pode aportar o uso de referências identificativos nacionais no desenho de recipiente e comunicação. Atualmente, são poucos os casos em que esse potencial é explorado no desenho de peças que serão distribuídas diariamente no território nacional mexicano, sendo a mais comum encontrar mercadorias que reproduzam visual e conceitualmente várias tendências gráficas emanadas ou utilizadas o mercado norte-americano, tendo impacto em uma criação limitada e esporádica de valor através de marcas com identidade cultural mexicana, diluindo a possibilidade de dotá-los de um alto valor simbólico, histórico e comunicacional.

Palavras chave: Identidade mexicana - Desenho de envase - Desenho nacional - Feito no México - Referências prehispánicas.

[Las traducciones de los abstracts fueron supervisadas por el autor de cada artículo] 